\title{
An in vitro comparison of a novel Self-Assembling Peptide Matrix Gel and selected desensitizing toothpastes in reducing fluid flow by dentine tubular occlusion
}

\author{
Robert G Hill \\ Queen Mary University of London \\ Helen Chen
}

The University of Manchester

Dominikus A Lysek

Credentis

David Gillam ( $\sim$ d.g.gillam@qmul.ac.uk)

Barts and The London School of Medicine and Dentistry https://orcid.org/0000-0002-8669-6138

\section{Research article}

Keywords: Self-Assembling Peptide Matrix, desensitizing toothpastes, tubular occlusion, hydraulic conductance

Posted Date: November 4th, 2019

DOI: https://doi.org/10.21203/rs.2.16822/v1

License: (9) This work is licensed under a Creative Commons Attribution 4.0 International License. Read Full License

Version of Record: A version of this preprint was published at Journal of Dental and Maxillofacial Research on February 14th, 2020. See the published version at https://doi.org/10.31038/JDMR.2020311. 


\section{Abstract}

Background: The objective of the present in vitro study was to evaluate the ability of a novel selfassembling peptide matrix gel with calcium phosphate in effectively occluding dentine tubules compared to selected desensitizing toothpastes.

Methods: Mid-coronal dentine discs with a thickness of $1 \mathrm{~mm}$ were sectioned from caries-free human molars. The discs were etched with $6 \%$ citric acid for 2 minutes, halved and subjected to a 2-minute brushing with a novel gel (SAPM) and three selected desensitizing toothpastes ([SRP], [SRR] and [CSP]). The ability of the desensitizing gel and toothpastes to occlude the dentine tubules was assessed and compared before and after brushing using Scanning Electron Microscopy (SEM) on both etched and fractured dentine surfaces. The SEM observations were supplemented by hydraulic conductance measurements using a modified Pashley model before and after tooth brushing $(n=5)$.

Results: The results demonstrated that there was a reduction in both the number and the diameter of the open dentine tubules, which was evident for all the treated dentine discs. The particles that occluded the open dentine tubules, however had different morphologies and distribution. The self-assembling peptide matrix gel (SAPM) demonstrated the greater reduction in the number of open tubules compared to the other desensitizing toothpastes. Reductions in the hydraulic conductance measurements were observed for all tested materials (mean [SD, \%]: SAPM 55.1 [12.5], SRP 64.9 [18.5], SRR 39.1 [17.1] and CSP 27.6 [6.8]). No statistically differences were observed between the SAPM and SRP, SRR toothpastes (paired tTest; $\leq 0.05$ ) although a significant difference was noted between the SAPM and the CSP toothpastes. There was an overall trend for reduction for the SAPM compared to the SRR toothpaste.

Conclusion: The results would suggest that a novel self-assembling peptide matrix gel (SAPM) was effective in blocking the dentine tubules and may therefore have the potential to be an effective desensitizing product for the treatment of Dentine Hypersensitivity.

\section{Introduction}

According to Hill \& Gillam [1] Dentine Hypersensitivity (DH) is a clinical problem that may have impact on the Quality of Life of individuals who experience discomfort when eating and drinking hot and cold food during their day to day activities. The condition is postulated in the Hydrodynamic Theory [2] to be a result of minute fluid shifts within the dentine tubules following an external stimulus (e.g., cold, heat etc.). Currently toothpastes, gels and mouthwashes are designed to reduce or relieve pain arising from $\mathrm{DH}$ based on either their 1) tubular occluding components (e.g., silica, calcium carbonate, hydroxy- or nanohydroxy apatite(s), oxalates or bioactive glass) or 2) nerve desensitization properties (e.g., potassium ions). Most of today's commercial products have been reformulated from well-established technologies ([3-5]. One of the few new developments representing a biomimetic approach to remineralisation and thus being an alternative to the traditional desensitizing products for treating $\mathrm{DH}$, is a self-assembling peptide matrix (SAPM) gel. The biomimetic self-assembling peptide P11-4 (SAP P11-4) has been 
shown to be effective as a non-invasive treatment for early stage dental caries [6-12]. In the treatment of early caries SAP P11-4 has been shown to diffuse into the subsurface micro-pores of enamel and form a 3D scaffold/matrix/hydrogel thereby mimicking the enamel matrix original function during tooth development, to support apatite crystallization, thus reversing tooth decay $[6,8]$. According to previous reports SAP P11-4 (Ace-GIn-Gln-Arg-Phe-Glu-Trp-Glu-Phe-Glu-Gln-Gln-NH2) self-assembles into a matrix or hydrogel [13] under defined conditions. This matrix can support biomimetic mineralization and enamel regeneration [9]. The glutamic acid residues on the surface have been shown to act as nucleation sites for apatite formation and result in remineralisation of the lesion body [14].

The first product based on SAPM for treatment of Dentine Hypersensitivity (DH) has been marketed (Curodont D'Senz, Credentis ag, Switzerland). It has been recently shown to be effective in reducing DH in a randomised clinical study by Schlee et al. [15], demonstrating faster desensitisation than a toothpaste including 5\% Arginine and Calcium Carbonate. This product uses the same self-assembling peptide as included in the product for remineralisation carious lesion but was formulated as a gel with the selfassembling peptide in its assembled (i.e. matrix, SAPM) state. The SAPM is able to form a film on the dentine surface, without undergoing any chemical or physical transformation, solely by binding to the available Calcium ions on the tooth surface [14].

The in vitro measurement of fluid flow (hydraulic conductance [Lp]) in the dentine disk model has been used to assess the ability of desensitizing agents in treating Dentine Hypersensitivity (DH) [16]. According to Bränström [2] the mechanism underpinning the hydrodynamic theory is associated with rapid minute shifts in dentine fluid flow within the open dentine tubules, which acts as a capillary bore when a stimulus (e.g., cold) is applied to an exposed dentine surface. Fluid flow is dependent on the fourth power of the radius and therefore, any reduction in the diameter of the dentine tubule lumen should in theory reduce the fluid flow within the tubule, which in turn will decrease $\mathrm{DH}$ [16]. These investigators used a dentine section of approximately $1.0 \mathrm{~mm}$ in thickness to measure the hydraulic conductance of each desensitizing product applied on a dentine disc according to Greenhill \& Pashley [16].

The aim of the present in vitro study was to investigate the ability of a commercially available SAPM containing gel in occluding dentinal tubules and thus reducing hydraulic conductance (fluid flow) through dentine.

\section{Objectives}

The main objective of the present in vitro study was to access the ability of a novel SAPM gel in reducing fluid flow (hydraulic conductance [Lp]) by tubular occlusion and to compare the effectiveness of the SAPM to three desensitizing technologies incorporated into toothpastes with established tubular occluding properties e.g., Colgate Sensitive ProRelief, Sensodyne Repair and Protect, and Sensodyne Rapid Relief.

\section{Methods}


In the present experiments a modified Pashley cell was used (Figure 1) [10,17]. The fluid flow through the dentine discs was measured for the SAPM Gel and three selected desensitizing toothpastes (Table 1). The non-treated dentine discs were used as a control to the measurements obtained from the treated dentine discs.

\section{Dentine Disc preparation:}

Caries free extracted mandibular and maxillary molars were used for the study. Teeth were obtained from the tooth bank at the Royal London Dental Hospital under agreed Ethics Committee approval (QMREC 2011/99). Teeth were stored in a $3 \%$ sodium hypochlorite solution within the Department of Dental Physical Sciences under the Human Tissue Act (2004) regulations prior to the evaluation of the selected products.

The criteria for the teeth selection were as follows:

- Molar teeth.

- Large molar teeth, with a dentine area of at least $6 \mathrm{~mm}$ in diameter.

- Carious free.

The selected teeth were cleaned and stored in a $3 \%$ sodium hypochlorite solution (prepared from $14 \%$ sodium hypochlorite solution after dilution) for 24 hours to allow for disinfection. After the disinfection procedure, the teeth were stored in 70/30 ethanol/water prior to use. Each tooth was fixed in a sample holder using impression material compound (Kerr, Model: 813-00425) and placed perpendicular to the annular diamond coated blade of a precision slicer (Microslice II, Malvern Instruments, UK). The enamel crown was discarded, and the cutting continued below the dentine-enamel junction to produce discs consisting of dentine. The diamond blade was adjusted to result in discs with a thickness of $1 \mathrm{~mm}$. The prepared discs were then stored in 70/30 ethanol/water.

Figure 1

\section{Polishing, Cleaning and Etching of Dentine Discs}

Prior to the assembling of the dentine discs into the Pashley permeability holder (cell), they were polished, cleaned and etched. The polishing step was completed by wet polishing both sides of the dentine discs against a series of silicon carbide grinding paper (P800 - P4000 equivalent to $5 \mu \mathrm{m}$ ) using a polishing machine (Kent 4 Automatic Lapping \& Polishing Unit, Kemet International Ltd., UK). The thickness of the polished dentine disc was measured using a digital Vernier calliper (AK962EV, Sealey). The polished dentine discs were cleaned $(2 \times 5 \mathrm{~min})$ in an Ultrasonic bath (Kerry Ultrasonic bath), the water bath was changed after the first five minutes. 


\section{Dentine Tubule Occlusion evaluation by Scanning Electron microscopy (SEM)}

The dentine discs were etched ( $6 \%$ citric acid; $2 \mathrm{~min}$ ) and rinsed thoroughly with de-ionised water. Each test surface was marked and then fractured into two halves using dental pliers, one half was used as a control, and the other half was subjected to two minutes brushing with $0.1 \mathrm{ml}$ toothpaste by an electrical toothbrush with a sensitive brush head (Oral-B Trizone 5000, UK). Following brushing, the discs were rinsed by water and dried in air. All four test products described in Table 1 were evaluated and new brush heads were used for each of the test toothpastes.

The control-half dentine disc and the test-half treated were again halved into quarter discs. A quarter from each half was prepared for SEM analysis. The specimens were gold coated and viewed under a field emission scanning electron microscope (FEl Inspect F, Oxford Instruments, Oxfordshire, UK) in the secondary scanning imaging mode at a voltage of $10 \mathrm{KV}$ and a working distant of $10 \mathrm{~mm}$.

The deposit on the surface of the dentine and the distribution of the particles around and within the dentine tubules was investigated. SEM images were taken at the same region (close to the centre of the dentine disc) of the control and treated dentine disc with same magnification(s) (2000x, x 5000x, 10,000x and $20,000 x$ ) to evaluate the effectiveness of the ability of each toothpaste in occluding the dentine tubules. A cross section of a dentine disc was prepared by cutting one dentine disc in half using dental pliers [17]. The section designated the 'test' half was treated by applying the SAPM gel as previously described and viewed under the SEM.

\section{Permeability Measurement (Hydraulic Conductance [Lp])}

Following cleaning, the dentine discs were prepared as described for SEM analyses. The etched dentine disc was then placed in the Pashley specimen holder and prepared for the measurement of dentine permeability (hydraulic conductance). An air bubble ( $0.1 \mathrm{ml}$ gas) was introduced into the system via a disposable plastic syringe, which then passed through the tubing and traversed the micro-capillary set up. The distance (in $\mathrm{cm}$ ) that the air bubble travelled in the micro-capillary was recorded in one min intervals. Overall a continuous 10 min measurement was performed. The distance that the air bubble travelled was plotted against time, where a linear correlation was expected. The slope of the linear relationship was the fluid flow rate for the acid etched dentine disc.

The toothpaste residual was rinsed by water for five seconds and the fluid flow measurements were repeated in the same manner as described previously. The percentage reduction of the fluid flow was calculated using the following equation and presented in percentage (\%).

[Please see supplementary files for formula]

The selected desensitizing toothpastes investigated in the present study are listed in Table 1. 20 dentine discs were used for the permeability aspect of the study. Five discs were used in each of the four 
toothpaste groups.

Table 1: The desensitizing toothpastes investigated in the study

\begin{tabular}{|c|c|c|}
\hline Toothpaste Investigated & Company & Principal Ingredients \\
\hline $\begin{array}{l}\text { Self-Assembling Peptide Matrix Gel (Curodont } \\
\text { D'Senz/Protect)(SAPM) }\end{array}$ & Credentis & $\mathrm{P} 11-4$ \\
\hline \multirow[t]{2}{*}{ Colgate Sensitive ProRelief (CSP) } & \multirow{2}{*}{$\begin{array}{l}\text { Colgate } \\
\text { Palmolive }\end{array}$} & Pro-Argin(5\% Arginine) \\
\hline & & Calcium Carbonate \\
\hline Sensodyne Repair and Protect (SRP) & $\begin{array}{l}\text { GSK Consumer } \\
\text { Healthcare }\end{array}$ & $\begin{array}{l}\text { Calcium phosphosilicate } \\
\text { (Novamin) Bioactive Glass }\end{array}$ \\
\hline Sensodyne Rapid Relief (SRR) & $\begin{array}{l}\text { GSK Consumer } \\
\text { Healthcare }\end{array}$ & Strontium Acetate* \\
\hline
\end{tabular}

*Current formulations include Stannous fluoride instead of strontium acetate

\section{Results}

Figures 2-4 show the SEM images of the dentine discs 1) control (un-brushed sections) and 2) after brushing with the tested toothpastes at 3 different magnifications (2000x, 5000x and 20,000x) and a 3) cross-sectional view of the dentinal tubuli. A magnification of 2000x gives an overall impression of the dentine tubules occlusion, where high magnification shows how the particles were distributed in and around the dentine tubules.

The dentine disc treated with SAPM showed almost complete dentine tubule coverage by placing a hydrogel film over the dentine surface. The dentine disc surface was rather smooth with some big clusters presumably Dicalcium Phosphate particles from the formulation (Figure 2-3).

Figures 2-3 Showing the hydrogel film of the SAPM gel covering the dentine surface: Figure 2 shows the top down view whilst Figure 3 shows the cross-section. The presence of large clusters was also observed which may be result of the deposition of dicalcium phosphate particles from the formulation.

SEM images of dentine tubules treated SAPM before (left) and after treatment (right) can also be observed in Figure 4.

CSP treated dentine discs showed levels of dentine tubule occlusion and a different morphology of the elongated particle, which has a tendency of forming clusters was observed (Figure 5).

The dentine disc treated with SRP (Figure 6) provided levels of occlusion, however, a large area of open dentine tubules was observed. A small amount of fine particles (submicron level) was also observed on the dentine surface. Large clusters of particles also occluded 
some of the tubules. In contrast, the specimen treated with SRR formulation (Figure 7) provided better coverage compared with the SRP formulation (Figure 6). It was clear that there was precipitation of particles within the dentinal tubules as well as on the dentine surface.

Figure 8 demonstrated the variation of the fluid flow reduction (FFR) of the five discs used following the application of SAPM Gel (39.4\%-65.7\%). The mean FFR for the SAPM Gel was $55.1 \%$ compared to the other desensitizing products (Table 2). The percentage of fluid flow reduction by the SAPM Gel was statistically higher than for CSP however no significantly differences were observed between the SAPM Gel and both SRP and SRR (paired t-test).

Table 2: Fluid Flow Reduction for the tested toothpastes $(\mathrm{n}=5)$

\begin{tabular}{|l|c|c|}
\hline Toothpaste & Mean FFR (\%) & SD (\%) \\
\hline SAPM Gel & $55.1^{\mathrm{a}}$ & 12.5 \\
\hline CSP & $27.6^{\mathrm{b}}$ & 6.8 \\
\hline SRP & $64.9^{\mathrm{ac}}$ & 18.5 \\
\hline SRR & $39.1^{\mathrm{ab}}$ & 17.1 \\
\hline
\end{tabular}

\section{Discussion}

According to Hill and Gillam [1] despite the vast array of commercial products designed either as professionally applied products or techniques (Dentist applied) or as over-the counter products (OTC) (Home use) there is no universally accepted product that can completely resolve $\mathrm{DH}$. The desensitising technologies evaluated in the current in vitro study included a novel self-assembling peptide matrix (SAPM) gel and three selected desensitizing toothpastes with established tubular occluding properties namely 1) a technology consisting of arginine, a naturally occurring amino acid, and an insoluble calcium compound, in the form of calcium carbonate (CSP), 2) a 45S5 bioactive glass formulation (SRP) and 3) a strontium acetate formulation (SRR).

The use of SAP P11-4 as a non-invasive regenerative treatment for early stage dental caries has been documented [3-12]. Recent reports on favourable remineralisation after SAPM application have been published [18-19]. A randomised clinical trial investigating an SAPM Gel (as investigated in this report) demonstrated fast relief of DH compared to the other formulations evaluated [15]. An in vitro study by João-Souza et al. [20] also compared the desensitizing effects of selected toothpastes-one daily toothpaste including a diluted SAPM formulation-under erosive conditions. 
The other three test products of the present study (CSP, SRP, and SRR) have also been documented as effective desensitizing toothpastes on the basis of both in vitro and in vivo evidence [3-4, 21-27].

The in vitro evaluation of desensitizing products was undertaken using the established methodology described by Greenhill \& Pashley [16] and Mordan et al. [17], although one of the limitations using dentine discs from different teeth is the variability between the discs particularly when investigating hydraulic conductance (see variability with the fluid low within the five discs). All the treated discs in the present study resulted in a reduction in the number and the size of open dentine tubules on the surface of the dentine disc. This would suggest that there was a degree of effective tubular occlusion within all groups. The particles that occluded the open dentine tubules, however had different morphologies and distribution across the disc surface. The SAPM gel demonstrated the highest tubuli occlusion compared to the other groups, based on the SEM analysis. The SEMs of the treated discs suggested that the tubule occlusion originated by the placement of a hydrogel film of SAPM on the tooth surface. Yet, it is important to supplement the evidence from the SEM data by relating it to the hydraulic conductance measurements, as this new type of surface occlusion might result in a different degree of fluid flow inhibition as seen by insoluble particles from the conventional desensitisation groups. It is also important to recognise that the occlusion by the SAPM gel, does not involve any chemical or physical reaction, whereas all the other products rely on a precipitation reaction within the dentinal tubuli. For example, according to several investigators, arginine in the CSP formulation has been postulated to form a calcium arginine complex with calcium carbonate on the tooth surface and within the dentine tubules [1, 4]. The chemistry of this process however is poorly understood and has not been characterized in any detail [1]. The 45S 5 bioactive glass composition in the SRP formulation was originally designed as a bone substitute and not as an additive in toothpastes for treating $\mathrm{DH}$. It has been postulated that the glass particles dissolve in the mouth releasing $\mathrm{Ca}^{2+}$ and $\mathrm{PO}_{4}{ }^{3-}$ ions forming a hydroxycarbonated apatite (HCA) on the tooth surface and as such may not be acid resistant for permanent tubuli occlusion [1]. The main mode of action of strontium acetate (and strontium chloride) (SRR) for treatment of DH, has been suggested to be by tubular occlusion although the actual effect attributed to strontium in clinical studies has yet to be defined [28]. Current formulations of SRR have replaced Strontium Acetate with Stannous Fluoride.

Most of the toothpastes evaluated in the present in vitro study exhibited very good tubule occlusion and fluid flow inhibition following tooth brushing, the exception being SRP that was less effective in occluding the dentinal tubules (Figs 4-8, Table 2). One possible reason for this observation was that in the mouth this toothpaste reacts with saliva to form hydroxyapatite and as such may perform more effectively in the clinical environment rather than in the in vitro setting, as has been shown in clinical trials $[23,25]$.

The reductions in the dentine hydraulic conductance measurements were observed for all tested materials (mean [SD, \%]: SAPM 55.1 [12.5], SRP 64.9 [18.5], SRR 39.1 [17.1] and CSP 27.6 [6.8]). No statistically differences were observed between the SAPM and SRP, SRR toothpastes (paired t-Test; $\leq 0.05$ ) although a significant difference was noted between the SAPM and the CSP toothpastes. There was an overall trend for reduction for the SAPM compared to the SRR toothpaste. 
Although the SAPM gel was effective in the present study compared to the other tested products there is yet only one report of a randomised clinical trial comparing its clinical efficacy to that of the CSP product [15]. An additional in vitro study has evaluated a SAPM gel in a daily erosion toothpaste (with a much lower concentration of SAPM) [20], where the investigators reported that none of the desensitizing products showed any significant effects on tubular occlusion under the erosive conditions used. There are, however, significant differences in the methodology used in this study [20] compared to the current study. For example, the specimens were submitted to a 5-day erosion-abrasion cycling model and the fluid flow reductions were not shown as a time dependent graph, but rather as a value (with uncommonly large error bars). Furthermore, the toothpaste used in the João-Souzaa et al. study [20] included SAP P11-4 at a significantly lower level than the product investigated in the current study. It would therefore be of interest to compare these two SAPM containing products in a future study to determine their individual effects on tubular occlusion and identify the optimal concentration and application frequency for SAPM.

\section{Conclusion}

The results from the current in vitro study would suggest that a novel self-assembling peptide matrix gel was effective in occluding the dentine tubules and may therefore have the potential to be an effective desensitizing product for the treatment of dentine hypersensitivity.

\section{Declarations}

\section{Acknowledgement}

The research was funded by Credentis AG, Switzerland

\section{Declarations}

\section{Ethics approval and consent to participate}

Teeth were obtained from the tooth bank at the Royal London Dental Hospital under agreed Ethics Committee approval (QMREC 2011/99)

\section{Consent for publication}

Not applicable. The teeth used in the study were from anonymised sources as covered by the Ethics Approval

\section{Availability of data and materials}


The datasets used and/or analysed during the current study are available from the corresponding author on reasonable request.

\section{Competing interests}

Dr Dominikus A. Lysek is the CEO of Credentis AG, Switzerland who funded the study

\section{Funding}

The study was funded by Credentis AG, Switzerland

\section{Authors' contributions}

RGH, DGG and DAL contributed to the conception and design of the study, $\mathrm{HC}$ was the main contributor in conducting the in vitro study. All authors contributed to the interpretation of the data and results and the initial drafting of the manuscript. DGG, RGH and DAL finalised the agreed submitted manuscript

\section{Acknowledgements}

As above the study was funded by Credentis AG, Switzerland

\section{References}

1. Hill RG \& Gillam DG: Future strategies for the development of desensitising products. In: Dentine Hypersensitivity: Advances in Diagnosis, Management, and Treatment. Chapter 11, David G. Gillam (ed). DOI 10.1007/978-3-319-14577-8, @ Springer International Publishing Switzerland. 2015 Pages 157-179.

2. Brännström M. A hydrodynamic mechanism in the transmission of pain-produced stimuli through the dentine. In: Anderson D.J. (ed) Sensory mechanisms in dentine. Pergamon, Oxford, pp 73-79, 1963.

3. Cummins D. Dentin hypersensitivity: from diagnosis to a breakthrough therapy for everyday sensitivity relief. J Clin Dent, 2009; 20 (Special Issue):1-9

4. Cummins $D$. Recent advances in dentin hypersensitivity: Clinically proven treatments for instant and lasting sensitivity relief. Am J Dent 2010;23 Sp Is A:3A-13A.

5. Gillam DG Chapter 5 Treatment Approaches for Dentin Hypersensitivity. In S. Taha, B.H. Clarkson (eds.), Clinician's Guide to the Diagnosis and Management of Tooth Sensitivity, DOI 10.1007/978-3642-45164-5_5, @ Springer-Verlag Berlin Heidelberg 2014, pp 51-79. 
6. Kirkham J, Firth A, Vernals D, Boden N, Robinson C, Shore RC, Brookes S.J, Aggeli A. Self-assembling peptide scaffolds promote enamel remineralisation J Dent Res 2007, 86, 426-430.

7. Brunton, PA, Davies, RPW, Burke JL, Smith, A, Aggeli, A, Brookes SJ and Kirkham J. Treatment of early caries lesions using biomimetic self-assembling peptides - a clinical safety trial. Brit Dent $J$ 2013, 215:1-6.

8. Kind, L., Stevanovic, S., Wuttig, S., Wimberger, S., Hofer, J., Müller, B., \& Pieles, U. Biomimetic Remineralization of Carious Lesions by Self-Assembling Peptide. J Dent Res, $2017 ; 96$ (7), 790-797.

9. Alkilzy M, Tarabaih A, Santamaria RM, Splieth CH. Self-assembling Peptide P11-4 and Fluoride for Regenerating Enamel. J Dent Res 2018, 97148-154.

10. Chen X, Gillam DG, Lysek DA, Hill RG. In Vitro Evaluation of Dentine Remineralisation by a SelfAssembling Peptide Using Scanning Electron Microscopy. 61th ORCA Congress July 2-5, 2014, Greifswald, Germany, Abstract no. 40.

11. Schlee M, Schad T, Koch JH, Cattin PC, Rathe F. Clinical performance of self-assembling peptide P114 in the treatment of initial proximal carious lesions: A practice-based case series. J Invest Clin Dent 2018; 9:e12286. wileyonlinelibrary.com/journal/jicd https://doi.org/ 10.1111/ jicd.12286.

12. Bröseler F, Tietmann $C$, Bommer $C$, Drechsel T, Heinzel-Gutenbrunner $M$, Jepsen $S$. Randomised clinical trial investigating self-assembling peptide P11-4 in the treatment of early caries. Clin Oral Investig. 2019 Apr 29. doi: 10.1007/s00784-019-02901-4. [Epub ahead of print].

13. Aggeli A, Bell M, Boden N, Carrick LM, Strong AE. Self-assembling peptide polyelectrolyte beta-sheet complexes form nematic hydrogels. Angew Chem Int Ed Engl. 2003 Nov 24;42(45):5603-6

14. Saha, S. Yang, X.B. Wijayathunga, N. Harris, S. Feichtinger, G.A. Davies, R.P.W. Kirkham, J. A biomimetic self-assembling peptide promotes bone regeneration in vivo: A rat cranial defect study. Bone 2019: 127; 602-611.

15. Schlee M, Rathe F, Bommer C, Bröseler F, Kind L. Self-assembling peptide matrix for treatment of dentin hypersensitivity: A randomized controlled clinical trial. J Periodontol 2018: 89; 653-660.

16. Greenhill JD, Pashley DH. The Effects of Desensitizing Agents on the Hydraulic Conductance of Human Dentin in vitro. J Dent Res 1981: 60; 686-98.

17. Mordan NJ, Barber PM, Gillam DG. The dentine disc. A review of its applicability as a model for the in vitro testing of dentine hypersensitivity. J Oral Rehabil 1997; 24:148-156.

18. Soares R, de Ataide IDN, Fernandes M, Lambor R. Assessment of Enamel Remineralisation with different Remineralising Agents. Journal of Clinical and Diagnostic Research. 2017, 11: ZC136ZC141.

19. Jablonski-Momeni A, Korbmacher-Steiner $H$, Heinzel-Gutenbrunner $M$, Jablonski B, Jaquet W, Bottenberg P. Randomised in situ clinical trial investigating self-assembling peptide matrix P11-4 in the prevention of artificial caries lesions. Scientific Reports 2019 9:269 | DOI:10.1038/s41598-01836536-4. 
20. João-Souzaa SH, Scaramuccia T, Borges AB, Lussic A, Carvalhoc TS, Aranhaa ACC. Influence of desensitizing and anti-erosive toothpastes on dentine permeability: An in vitro study. $J$ Dent (in press).

21. Sharif M, Iram S, Brunton P. Effectiveness of arginine containing toothpastes in treating dentine hypersensitivity: A systematic Review. J Dent. 2013; 41: 483-492.

22. Yan B, Yi J, Li Y, Chen Y, Shi Z. Arginine-containing toothpastes for dentin hypersensitivity: systematic review and meta-analysis. Quintessence International 2013; 44(9): 709-723.

23. Ramamoorthi S, Nivedhitha MS. Effectiveness of Bioactive glass Containing Dentifrice on Dentin Hypersensitivity - A Systematic Review. JPR:BioMedRx. An International Journal 2013,1(8),803-809.

24. Karim BFA, Gillam DG. The Efficacy of Strontium and Potassium Toothpastes in Treating Dentine Hypersensitivity: A Systematic Review. Int J Dent. 2013; 2013: 573258.

25. Talioti E, Hill R, Gillam DG. The Efficacy of Selected Desensitizing OTC Products: A Systematic Review. ISRN Dent. 2014; 2014: 865761.

26. Gillam DG Treatment Approaches for Dentin Hypersensitivity. In Chapter 5 Clinician's Guide to the Diagnosis and Management of Tooth Sensitivity S. Taha, B.H. Clarkson (eds.), DOI 10.1007/978-3642-45164-5_5, (c) Springer-Verlag Berlin Heidelberg 2014, pp 51-79.

27. Hu M-L, Zheng G, Zhang Y-D, Yan X, Li X-L, Lin H. Effect of desensitizing toothpastes on dentine hypersensitivity: A systematic review and meta-analysis. J Dent, 2018, 12-21.

28. Rösing CK, Fiorini T, Liberman DN, Cavagni J. Dentine hypersensitivity: analysis of self-care products. Braz Oral Res. 2009; 23 Suppl 1:56-63.

\section{Tables}

Table 1: The desensitizing toothpastes investigated in the study

\begin{tabular}{|l|c|c|}
\hline \multicolumn{1}{|c|}{ Toothpaste Investigated } & Company & Principal Ingredients \\
\hline $\begin{array}{l}\text { Self-Assembling Peptide Matrix Gel (Curodont } \\
\text { D'Senz/Protect)(SAPM) }\end{array}$ & Credentis & Pro-Argin(5\% Arginine) \\
\hline Colgate Sensitive ProRelief (CSP) & $\begin{array}{c}\text { Colgate } \\
\text { Palmolive } \\
\text { Calcium Carbonate }\end{array}$ \\
\hline Sensodyne Repair and Protect (SRP) & $\begin{array}{c}\text { GSK Consumer } \\
\text { Healthcare }\end{array}$ & $\begin{array}{c}\text { Calcium phosphosilicate } \\
\text { (Novamin) Bioactive Glass }\end{array}$ \\
\hline Sensodyne Rapid Relief (SRR) & $\begin{array}{c}\text { GSK Consumer } \\
\text { Healthcare }\end{array}$ & Strontium Acetate* \\
\hline
\end{tabular}

\footnotetext{
*Current formulations include Stannous fluoride instead of strontium acetate
}

Table 2: Fluid Flow Reduction for the tested toothpastes $(n=5)$ 


\begin{tabular}{|l|c|c|}
\hline Toothpaste & Mean FFR (\%) & SD (\%) \\
\hline SAPM Gel & $55.1^{\mathrm{a}}$ & 12.5 \\
\hline CSP & $27.6^{\mathrm{b}}$ & 6.8 \\
\hline SRP & $64.9^{\mathrm{ac}}$ & 18.5 \\
\hline SRR & $39.1^{\mathrm{ab}}$ & 17.1 \\
\hline
\end{tabular}

\section{Figures}
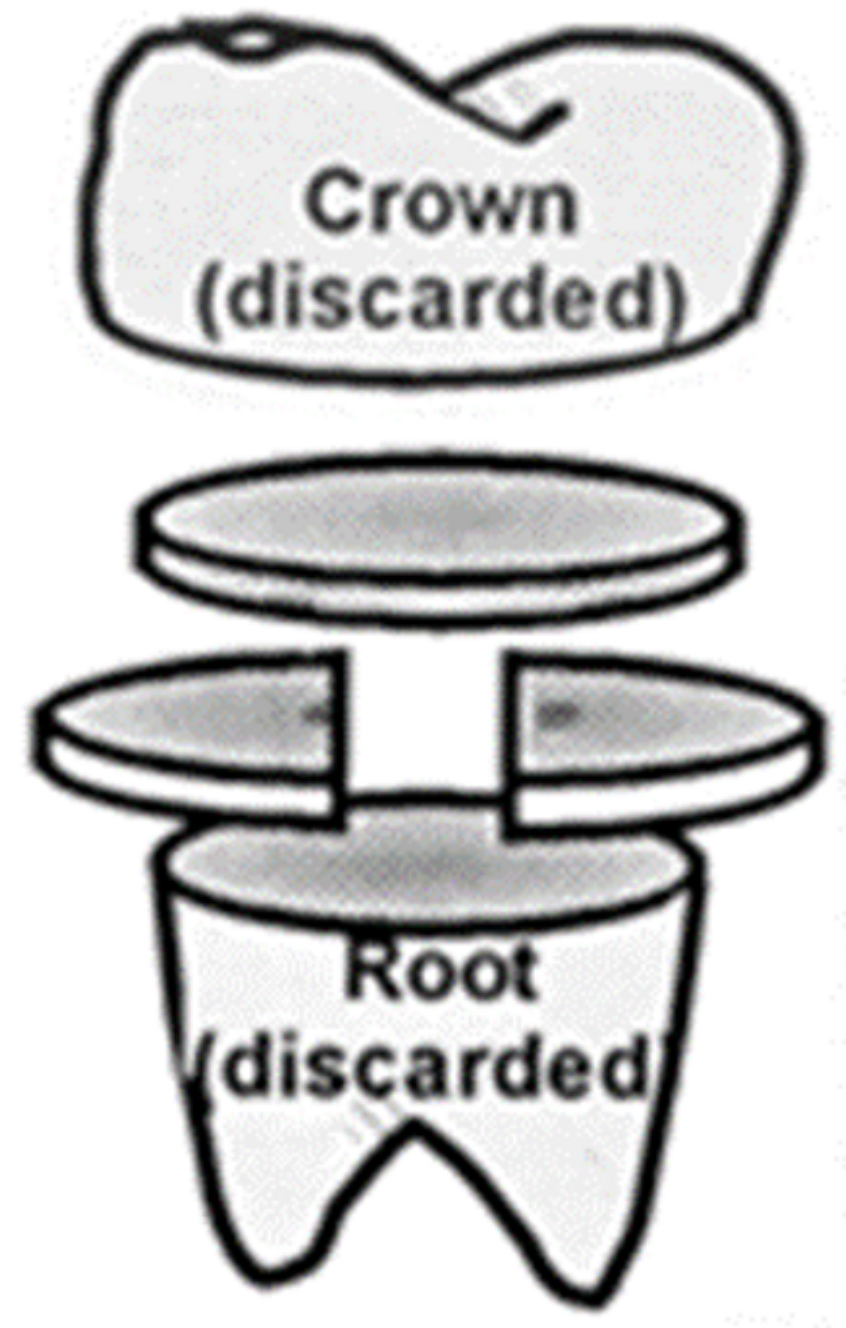

Figure 1

Dentine Disc Preparation (Based on Mordan et al., [17]). 


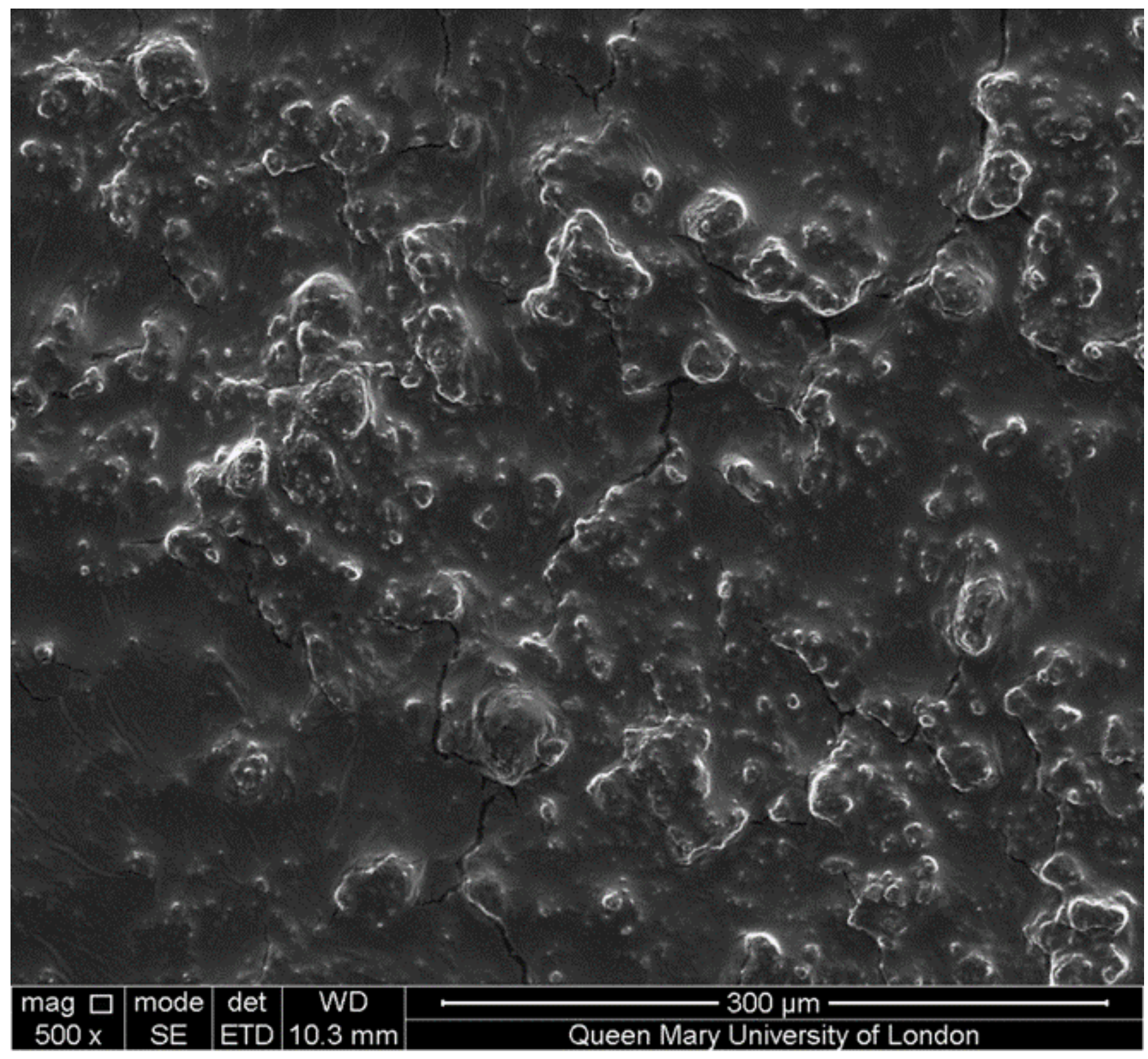

\section{Figure 2}

Showing the hydrogel film of the SAPM gel covering the dentine surface: Figure 2 shows the top down view whilst Figure 3 shows the cross-section. The presence of large clusters was also observed which may be result of the deposition of dicalcium phosphate particles from the formulation. 


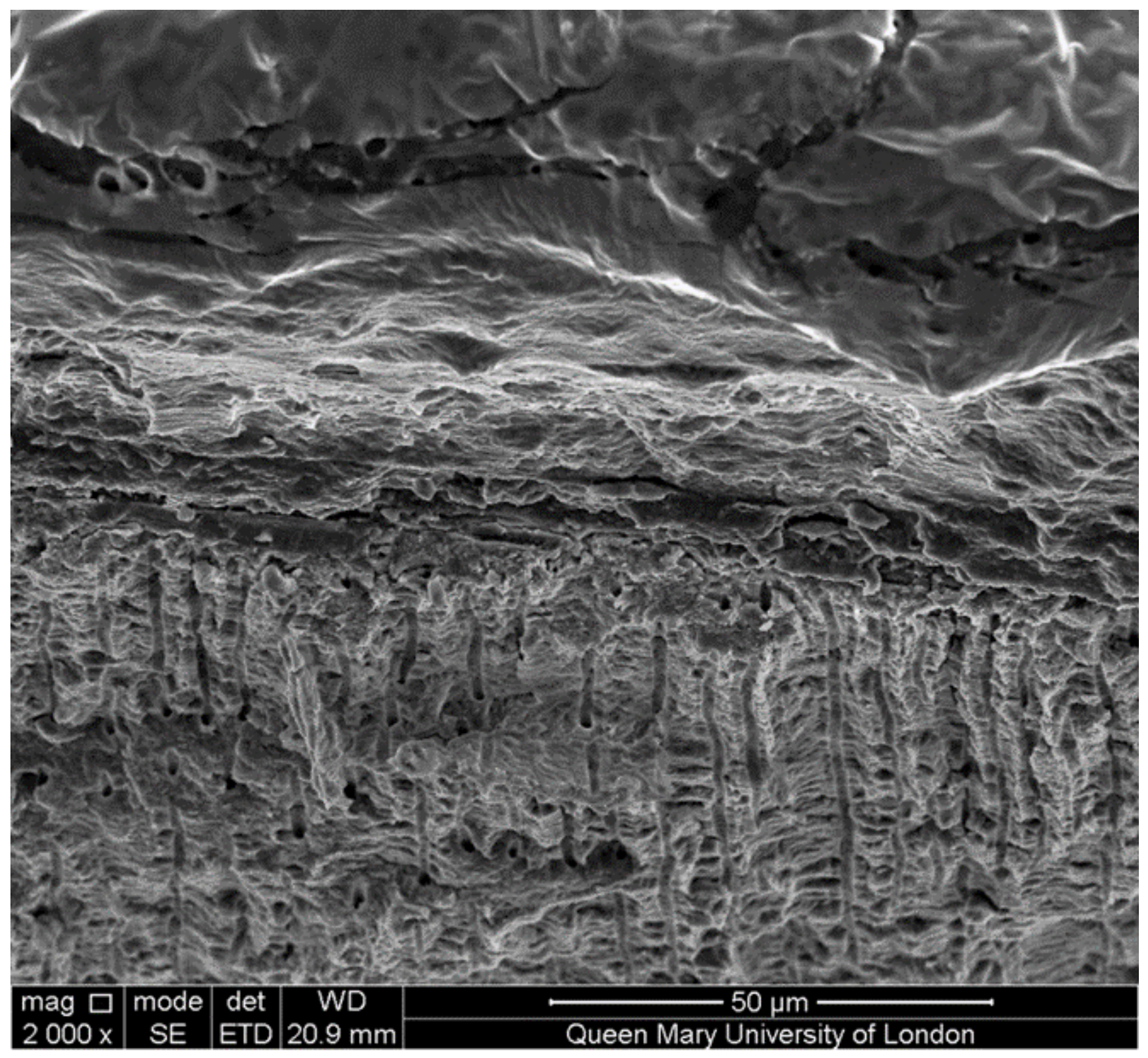

\section{Figure 3}

Showing the hydrogel film of the SAPM gel covering the dentine surface: Figure 2 shows the top down view whilst Figure 3 shows the cross-section. The presence of large clusters was also observed which may be result of the deposition of dicalcium phosphate particles from the formulation. 

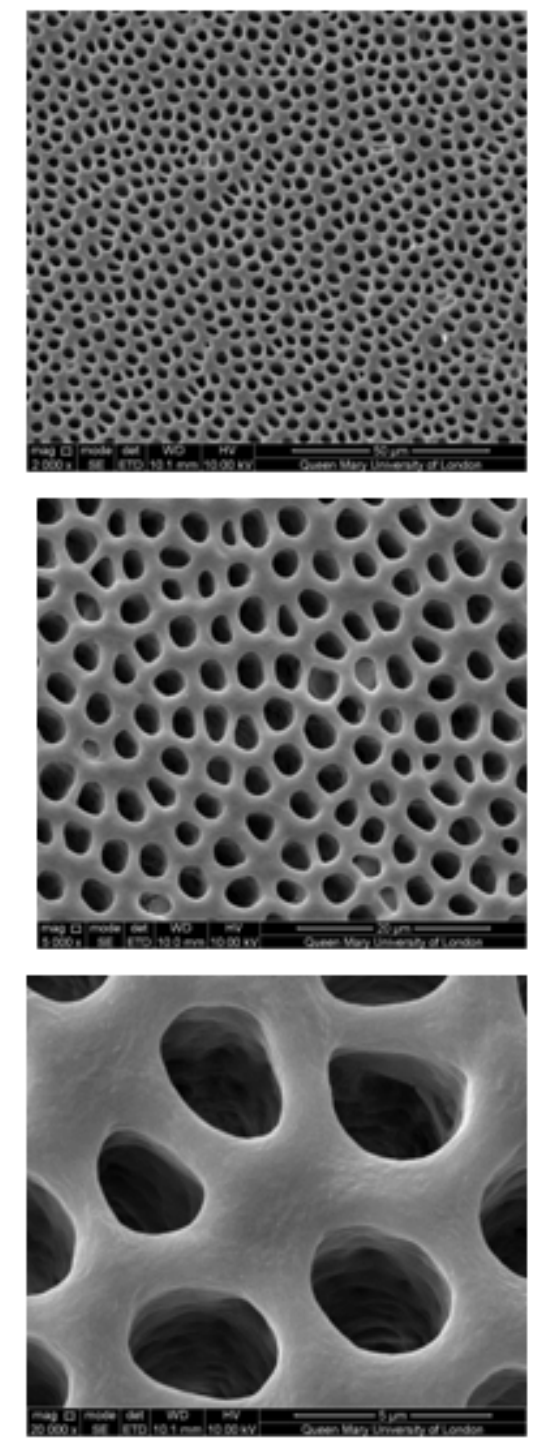

Figure 4

SEM images of dentine tubules treated with self-assembling peptide matrix (SAPM) before treatment (left) and after treatment (right) 

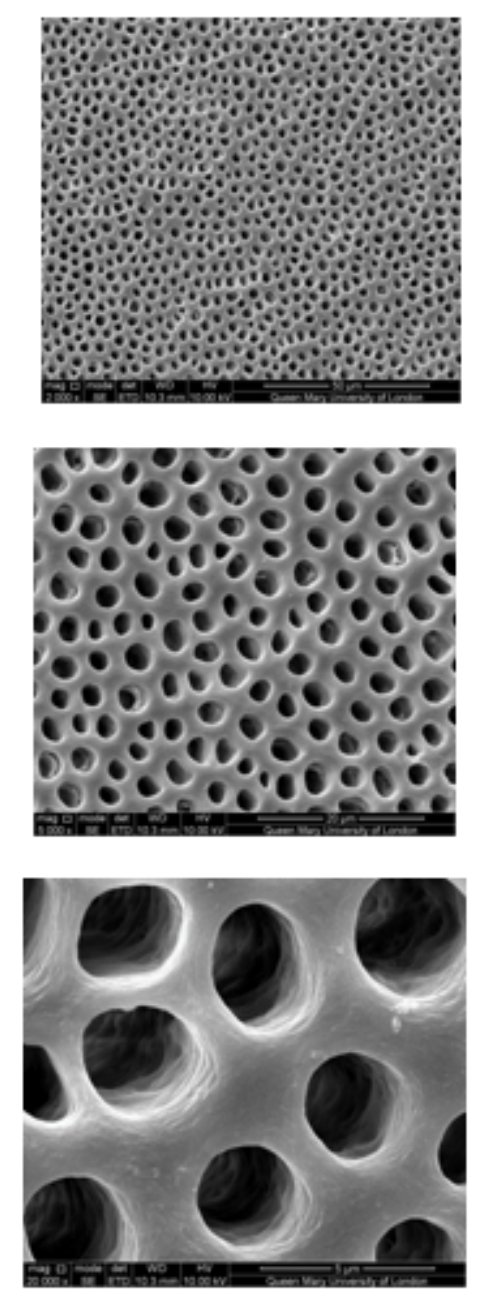
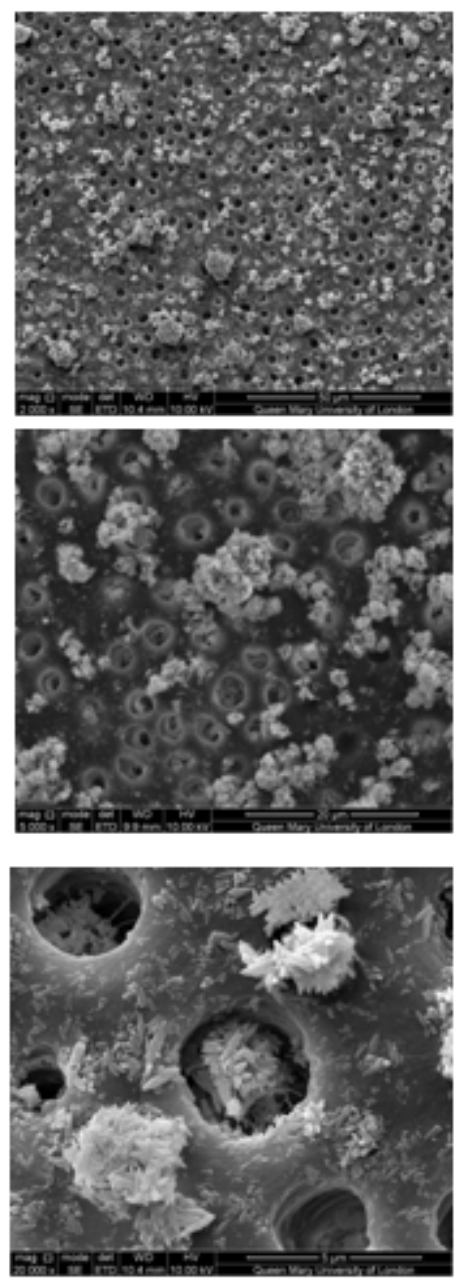

Figure 5

SEM images of dentine tubules treated with Colgate Sensitive ProRelief Toothpaste, before treatment (left) and after treatment (right) 

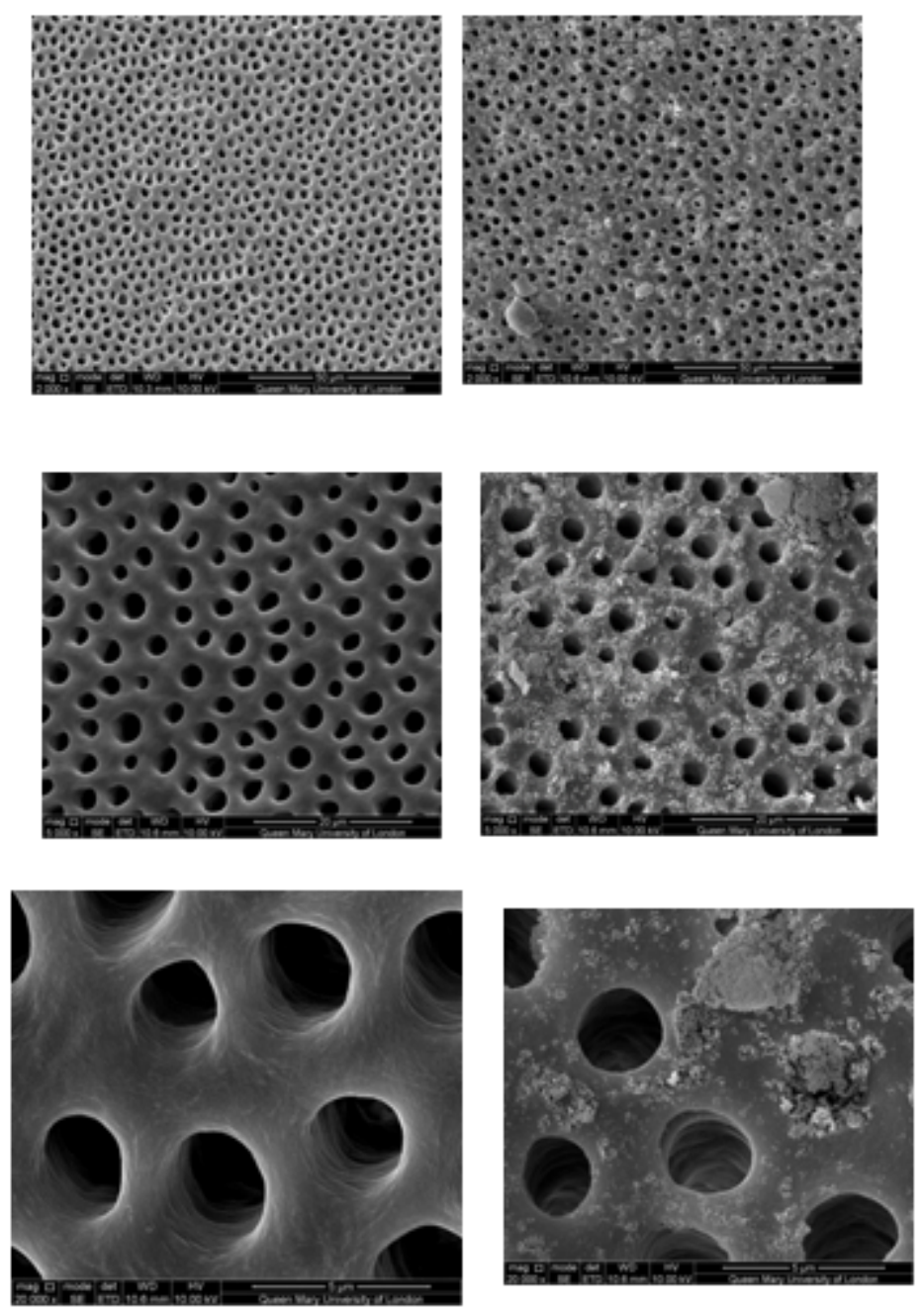

Figure 6

SEM images of dentine tubules treated with Sensodyne Repair and Protect Toothpaste, before treatment (left) and after treatment (right) 

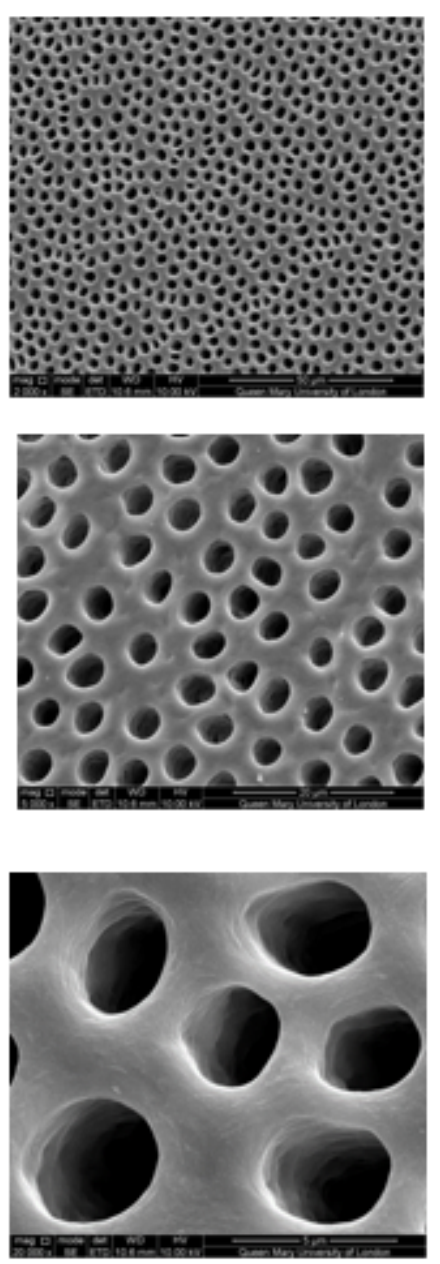
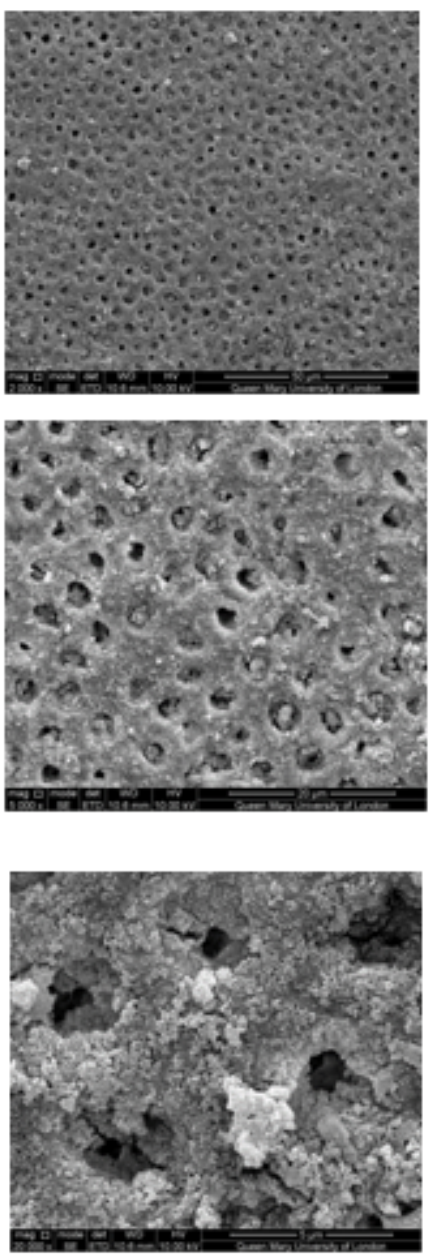

Figure 7

SEM images of dentine tubules treated with Sensodyne Rapid Relief Toothpaste, before treatment (left) and after treatment (right) 


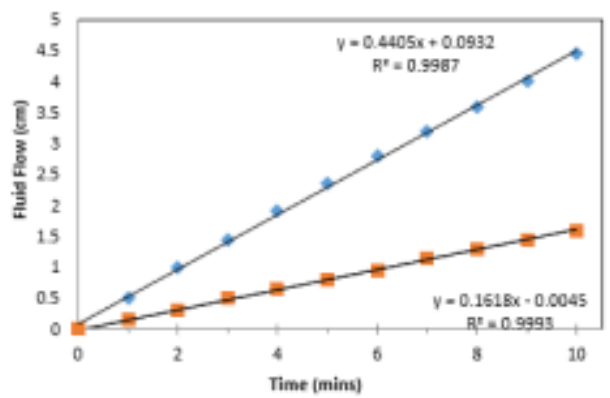
$65.7 \%$ reduction in fluid flow

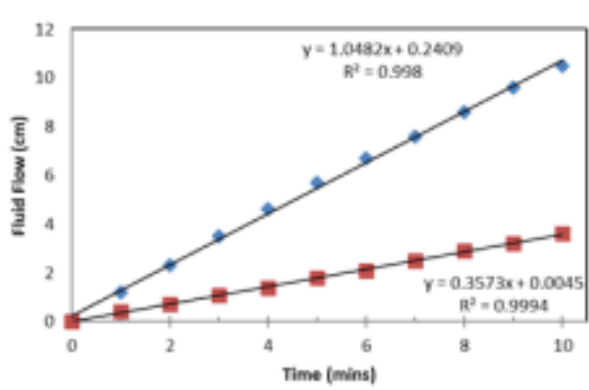

Dentine dise 3 treated with the SAPM Gel showing $39.4 \%$ reduction in fluid flow
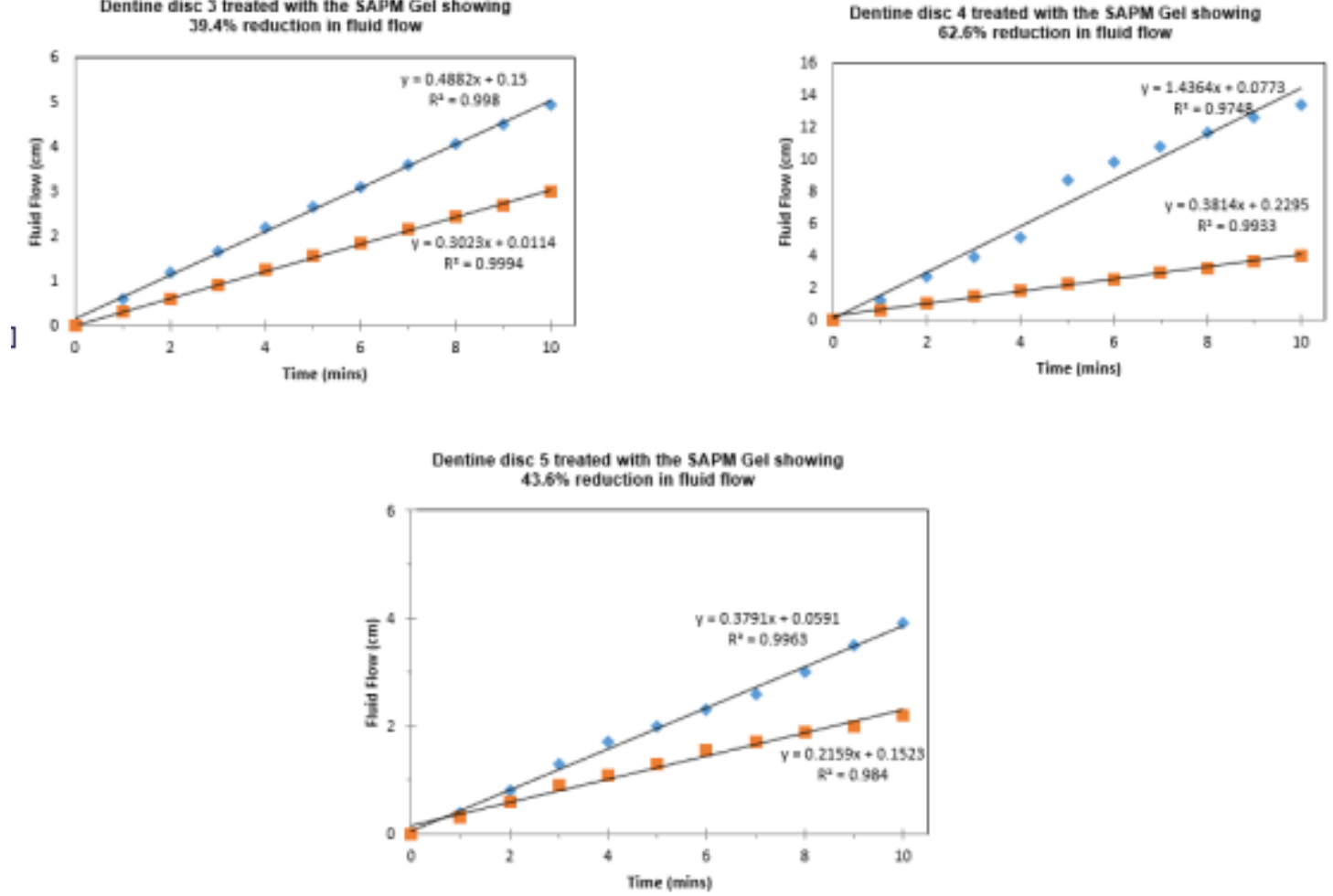

Figure 8

Plot showing the fluid low changes of dentine discs after 2 min brushing with the SAPM Gels (discs 1-5), where blue diamond represents etched control, and red square for after treatment (Fluid Flow Reduction [FFR] range: $39.4 \%-65.7 \%)$.

\section{Supplementary Files}

This is a list of supplementary files associated with this preprint. Click to download.

- Methodsformula.docx 